\title{
Arterial Thrombosis
}

National Cancer Institute

\section{Source}

National Cancer Institute. Arterial Thrombosis. NCI Thesaurus. Code C98826.

Formation of a blood clot in the lumen of an artery. 